\title{
ADMINISTRATIVAS
}

\section{A Mesa Redonda de Lisboa do Instituto Internacional de Ciências Administrativas}

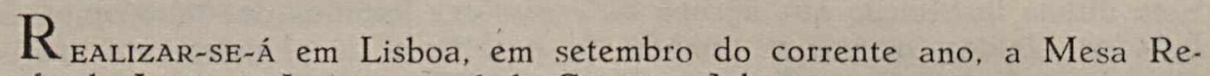
donda do Instituto Internacional de Ciências Administrativas.

Essa reunião internacional, preparatória do XII Congresso Internacional de Ciências Administrativas a realizar-se no próximo ano de 1962 , terá por objetivo examinar e discutir os relatórios nacionais preliminares apresentados em obediência aos questionários elaborados pelo IICA durarte e após o Colóquio de San Remo, de 1960, e recebidos pelas Seções Nacionais do IICA em fins do mesmo ano.

Após os referidos exame e discussão, serão traçados os planos para os relatórios gerais de cada tema, englobando os relatórios nacionais e compreendendo ainda, se necessário, informações adicionais que forem solicitadas. Em 1962, os relatórios gerais serão, então, discutidos.

Dä Mesa Redonda de 1961, participarão apenas os Relatores-Gerais, os membros das Comissões permanentes do IICA e do Conselho de Administração, bem como os Relatores Nacionais dos três temas.

O IBCA convidou, para Relatores Nacionais, o Prof. Benedicto Silva (tema I), D. Lidia Sambaquy (tema II) e o Dr. Cleantho Leite. (tema III), que aceitaram o convite e estão elaborando os respectivos relatórios.

São os seguintes os temas e seus questionários:

Tema I - Assistência técnica em Administração Pública - lições de experiência e possiveis melhoramentos.

\section{Questionário}

1. Definições.

11. A finalidade da assistência técnica em administração pública: «Assistência técnica» consiste em proporcionar conhecimento, padrões e meios materiais necessários a uma boa administração.

12. Definição de «Administração Pública».

Administração é o processo de dirigir, gerir e supervisionar um determinado grupo de pessoas e patrimônio.

Administração Pública é a parte da Administração que se ocupa com os Estados, ou comunidades regionais, ou instituições públicas e emprêsas nacicnais. 
2. Organização.

21. Os fins e objetivos da assistência técnica em administração pública.

21.1 Quais os principais fins e objetivos da assistência técnica que o seu pais recebe ou proporciona?

21.11 Reorganização e reforma administrativa para:

a) Remoção de deficiências que surgiram no atual mecanismo administrative e em seu funcionamento, com vistas à melhoria da eficiência e da economia

b) Criação, expansão e melhoramento de serviços e práticas administrativas, a fim de fazer face ao aumento do volume e importância das tarefas administrativas tradicionais.

21.12 Administração para o desenvolvimento:

Criação de nôvo mecanismo administrativo para fazer face às novas funções de govêrno ou adaptação, para tal fim, do mecanismo já existente.

21.13 Para projetos destinados a melhorar as relaçõez entre os governos central, estaduais e municipais, e projetos especiais.

21.14 Quaisquer cutros projetos.

21.2 Estão as finalidades e os projetos de assistência técnica em administração pública, solicitados ou concedidos pelo seu país, relacionados com:

Planejamento a longo prazo para desenvolvimento e'conônômico e social.

21.22 Maior associação e participação do pevo no processo administrativo.

21.23 Treinamento.

21.24 Finalidades especificas, limitadas quanto a seu escopo e conteúdo?

22. A base formal ( «formal basis») da assistência técnica.

22.1 A base formal no nivel nacicnal:

22.11 Qual a base formal de assistência técnica em administração pública recebida ou proporcionada por seu país?

a) Legal.

b) Cooperação ou acôrdos bilaterais entre dois Governos.

c) Acôrdos multilaterais.

d) Acôrdos cu pactos regionais.

e) Representação em organização internacional.

f) Doações de órgão ou fundação particular estrangeira. 
22.2 A base formal no nivel internacional.

22.21 Qual a base formal de assistência técnica, no nivel internacional, recebida ou proporcionada por seu país?

22.22 O pedido de assistência técnica vincula ambas as partes? Até que ponto pode o pedido ser modificado ou cancelado e quais as conseqüências?

22.3 Compromissos financeiros e de outra natureza relativa a assistência técnica.

22.31 Quais são, em geral, os compromissos financeiros de diferentes tipos de assistência técnica, solicitados ou proporcionados por seu pais?

22.32 Indique quaisquer outros compromissos, se houver.

23. Órgãos que proporcionam assistência técnica.

23.1. Qual a natureza, o montante e a duração da assistência em administração pública recebida ou proporcionada por seu pais, através dos seguintes órgãos e instituições?

23.11 Nações Unidas e seus órgãos especializados.

a) Sob o Programa Regular de Assistência Técnica.

b) Sob o Programa Extensivo de Assistência Técnica (ETAP).

c) O Fundo Especial das Nações Unidas.

23.12 Administração da Cooperação Internacional dos E.U.A. (ICA).

23.13 Programa da Comunidade para Cooperação Técnica (Plano Colombo).

23.14 Outros acôrdos bilaterais ou multilaterais.

23.15 Fundações particulares (exemplo, Fundação (Ford).

23.2 Através de que canais seu país concede ou recebe assistência?

23.21 Governamentais.

23.22 Universidades e outras instituições educacionais.

23.23 Outras instituições.

3. Programas e Projetos.

31. Natureza e finalidade da assistência.

31.1 Indique a assistência técnica em administração pública dos tipos abaixc, que tiver sido concedida ou recebida:

31.11 Consultoria.

31.12 Treinamento.

31.13 Operacional (e.g., consoante o Plano OPEX das Nações Unidas, etc.) 
31.2 Indique a assistência que tiver sido solicitada ou concedida a:

31.21 Ministérios e repartições governamentais.

31.22 Emprêsas estatais.

31.23 Universidades e outras instituições (em matéria de estudos, ensino e pesquisas sôbre administração pública) .

32. Assunto ou conteúdo.

32.1 Qual tem sido o principal tipo de assistência obtido por seu país durante os dez últimos anos nos seguintes aspectos funcionais do processo administrativo:

32.11 Organização governamental e gerência administrativa (inclusive planejamento e alta administraçãc).

32.12 Pessoal.

32.13 Administração financeira.

32.14 Relações públicas e participação pública.

32.15 Serviços Técnicos.

32.2 Qual a proporção da assistência nos diferentes aspectos programáticos da administração em relação à assistência total em administração pública, concedida ou recebida per seu país?

32.21 Administração de planejamento e desenvolvimentc.

32.22 Administração de recursos naturais.

32.23 Administração de recursos humanos.

32.24 Administração de desenvolvimento comercial e industrial.

32.25 Outros.

Qual a assistência, dada ou recebida, que tenha sido distribuida entre os seguintes órgãos-área do govêrno:

32.31 Govêrno central.

32.32 Estados.

32.33 Govêrno municipal.

Administração urbana.

Administração rural.

32.34 Regional?

33. Formas de Assistência.

33.1 Em que setores e até que ponto têm sido as seguintes formas de assistência utilizadas ou concedidas por seu pais?

33.11 Serviços de consultoria técnica, inclusive de natureza individual ou por meio de associações (e.g., universidades ou firmas de consultoria técnica) ou de grupos de técnicos mediante contratos mistos.

33.12 Bôlsas de estudo.

33.13 Institutos de treinamento. 
33.14 Conferências, seminários e oficinas de estudo.

33.15 Pesquisa e documentação técnica.

33.16 Empréstimo de pessoal operacional.

34. Organização administrativa, nos governos nacionais, para cuidar de assistência técnica.

Qual o mecanismo organizacional em seu pais para:

34.11 Coordenar as diversas propostas e solicitações de assistência técnica no setor da administração públi$\mathrm{ca}$ ? Se em um departamento governamental, qual?

34.12 Estabelecimentos de prioridades.

34.13 Contato e correspondência com órgãos ou governos estrangeiros que solicitem ou proporcionem assistência?

34.2 Até que ponto é a aprovação especifica do chefe do executivc, ou do gabinete de ministros, ou do órgão central de planejamento essencial à solicitação ou concessão de assistência técnica em administração pública?

34.3 Quais os métodos empregados para coordenação de issistência técnica com outros tipos de assistência (e.g., financeira, equipamento técnico, etc.) ?

4. Avaliação de Resultados.

41. Tem o seu país, de tempos a tempos, envidado esforços no sentido de avaliar os resultados de assistência técnica recebida ou proporcionada no setor de administração pública? Quais os padrões ou modelos estabelecidos para essa avaliação?

42. Tem -se cuidado de verificar, ocasional ou regularmente, o andamento do programa? Em caso afirmativc, a quem cabe êsse encargo?

43. Até que ponto têm sido considerados satisfatórios os resultados de diferentes formas de assistência técnica:

43. 1 Resultados diretos, tais como:

43.11 Metas físicas.

43.12 Padrões de qualidade.

43.13 Redução de custes.

43.14 Aumento na rapidez de prestação de assistência?

43.2 Resultados indiretos, tais como:

43.21 Criar uma consciência das fôrças que tenham influência sôbre a tomada de decisões administrativos.

43.22 Promover a compreensão da necessidade de se adaptarem práticas e métodos administrativos às exigências de modificações no serviço público, bem como entre os órgãos públicos e o povo em geral. 
43.23 Promover a adaptabilidade e flexibilidade administrativas.

43.24 Dar bases mais inteligiveis e racionais ao processo de tomada de decisões nas administrações nacional e estaduais.

43.25 «Efeito multiplicador» ou «reação em cadeia».

43.26 Impacto sôbre os planos a longo prazo do desenvolvimento econômico e social?

44. Acrescente quaisquer observações adicionais relativas à avaliação da eficiência da organização e objeto de assistência técnica.

\section{Melhoramentos no Sistema.}

51. Serviços de consultoria técnica (cf. 33.11):

- Seleção de técnicos.

- Orientação quanto a fatôres históricos, culturais, sociais e econômicos de subdesenvolvimento,

- Designação de setores específicos para receberem orientação,

- Orientação de experiências estrangeiras em setores semelhantes, trangeiro,

- Coordenação com outros técnicos,

- Indicação de pessoal nacional para servir junto a pessoal es-

- Ênfase sôbre recomendações substantivas,

- Assistência na execução.

52. Bôlsas de estudo (inclusive programas de treinamento em paises que não tenham assinado o acôrdo):

- Melhoria da seleção de candidatos com conhecimentos adequados, experiência e aptidões lingüisticas.

- Melhoria das instruções dadas ao bolsista antes da partida, sôbre os problemas que deverá estudar no exterior,

- Designação de programas especificos de estudo e treinamento em setor ou setores selecionados.

- Apresentação de relatório após a volta.

- Compromisso para trabalhar no mesmo setor, ou em outro correlato, por período mínimo, após treinamento ou estudo no exterior, dos estudos,

- Melhoria dos processos de «acompanhamento» («follow-up») terior.

- Cursos nacionais de atualização para pessoal treinado no ex-

53. Institutos de treinamentos:

- Orientação sôbre o contexto cultural, social e econômico específico ao pais, realistas,

- Ênfase sôbre esquemas de treinamento integrado e mais

- Estabelecimento de um mínimo de trabalho prático,

- Utilização crescente de auxilios áudio-visuais, 
- «Acompanhamento» durante o treinamento,

- Esquemas especiais de treinamento, e.g., para desenvolvimento executivo, serviço no exterior, desenvolvimento da comunidade, etc.

- Outras tarefas que lhes couberem.

54. Conferências, seminários e oficinas de estudo:

- Ênfase sôbre planejamento antecipado da programação e elaboração dos documentos de trabalho sôbre problemas específicos a serem submetidos a discussão.

- Necessidade de uma adequada publicidade prévia. bilitados.

- Limitação de participantes a individuos selecionados e ha-

- Formulação de recomendações e sua publicação.

- Implementação de recomendações.

55. Pesquisa e documentação técnica:

55.1 Assistêneia para:

- Adaptação de certos livros didáticos que não podem ser utilizados em determinados países,

- Compilação, em base estritamente internacional, de leituras clássicas de administração pública.

- Publicação de uma orientação metodológica sistemática sôbre material recolhido para estudo de casos.

- Compilação de bibliografia fundamental sôbre administração pública, sem consideração de fronteiras nacionais,

- Acesso a relatórios técnicos e outros materiais;

55.2 Fornecimento, em base internacional, de documentação especializada sôbre problemas específicos;

55.3 Ampla publicidade das pesquisas em andamento.

56. Empréstimo de pessoal de operações:

56.1 Setores em que pessoal estrangeiro pode ser utilizado com vantagem para tarefas operacionais;

56.2 Enfase sôbre pessoal nacional que deverá assumir as responsabilidades operacionais após a volta do pessoal estrangeiro.

57. Outras sugestões (por exemplo, estabelecimento de centros de treinamento regionais e internacionais).

6. Novo papel da Assistência Técnica.

61. Devolução administrativa:

61.1 Em que sentido tem sido útil a assistência técnica, ou em que sentido poderá sê-lo, na avaliação e solução das necessidades da administração para sua evolução? 
61.2 Qual a assistência específica recebida em assuntos de estudo e pesquisa em administração pública, e qual a que se faz necessária, a fim de adaptar o mecanismo e as práticas administrativas às necessidades de mudança?

62. No estudo comparado de administração pública:

Qual tem sido e qual será o impacto da assistência recebida ou proporcionada por seu país sôbre o estudo comparado de administração pública na região?

63. Funcionamento da administração pública em uma sociedade contemporânea:

Indique a interação entre a assistência técnica em administração pública, recebida ou proporcionada, e o funcionamento da administração pública sob a forma de govêrno de seu país. Quais são os prováveis desenvolvimentos futuros a êsse respeito? oficiais.

Tema II - Relações Públicas em Administração: publicações

\section{Questionário}

\section{Observação preliminar}

A finalidade do questionário abaixo é a de abranger todo o campo de relações entre as autoridades administrativas e o público. Entre todos os possiveis aspectos dêste amplo assunto, que deverá proporcionar matéria para pesquisas futuras, o IICA decidiu escolher como início de seu trabalho o estudo de' publicaçóes oficiais. De vez que o número e a natureza dessas publicações variam grandemente de um país para outro, bem como os regulamentos que as regem, pareceu necessário iniciar o estudo mediante um amplo que'stionário sôbre as mesmas. O IICA poderá então proceder a uma pesquisa comparada que possa, de futuro, servir de base para padronização e para torná-las mais bem adaptadas ao seu papel de informantes do público.

1. Escopo do assunto

A. Definição

Publicações oficiais, tal como se as compreende neste contexto, são publicações de responsabilidade das autoridades públicas ou entidades de direito público, na qualidade de autores ou editôres.

A fim de que a pesquisa se possa ater-se a limites, razoáveis, ficará restrita a publicações oficiais de órgãos centrais de Estados ou de federaçõe's de estados, bem como às de órgãos públicos nacionais.

B. Meios

As publicações podem ser de diversas formas: livros, periódicos, documentos mimeografados, gravuras, mapas, gravações em disco ou fita e programas radiofônicos. 
A pesquisa deverá preocupar-se sobretudo com publicações impressas.

C. Critérios pelos quais as Publicações Oficiais possam ser diferençadas.

11. Há qualquer critério de matéria, consoante a natureza e a finalidade da publicação?

11.1 Publicação de leis e decisões de autoridades administrativas militares e civis.

11.2 Coleções de tratados

11.3 Publicações parlamentares

11.4 Publicações de tribunais

11.5 Informações administrativas gerais, de natureza civil ou militar, tais como relatórios das atividades de serviços, documentos financeiros e contábeis, estatísticas, listas de pessoal e anuários administrativos, be'm como livros e periódicos que contenham informações gerais.

11.6 Informações gerais de natureza científica, educacional e técnica.

12. Critérios formais: autenticação pela chefia do órgão administrativo (simbolo ou timbre administrativo).

12.1 Há leis ou regulamentos que rejam o uso de símbolo ou timbre administrativo no frontispicio das publicações?

2. Os diferentes tipos de publicações oficiais

A. O Diário Oficial (Caso houver mais de um diário oficial, solicita-se resposta completa sôbre cada um)

21. Conteúdo

21.1 São publicadas apenas decisões de ordem geral, ou também decisões sôbre casos individuais?

21.2 São publicadas tôdas as decisões de natureza geral?

21.3 A publicação é feita e'm mais de um idioma? Em caso afirmativo, são tôdas as versões igualmente válidas?

21.4 Quem é responsável pela edição? Há uma unidade central que cuida de todos os textos destinados a publicação?

22. Qual a frequiência com que o diário é publicado?

23. Qual a sua fôrça legal?

23.1 Baseia-se em dispositivo legal sua publicação?

23.2 Quais as conseqüências de erros materiais?

23.3 Contém o diário anexos que não possuam a mesma fôrça jurídica?

23.4 São alguns avisos (editais) compulsórios? Em caso afirmativo, quais?

B. Outros meios de publicação de decisões governamentais.

24. Há outros meios de publicação das decisões?

25. Qual sua fôrça jurídica?

26. Qual a sua distribuição? 
C. Outras informações oficiais que não constituem decisões

27. São algumas publicações obrigatórias por leis ou regulamentos?

28. Com referência a outras publicações:

28.1 Possuem os serviços administrativos liberdade para décidir sôbre uma publicação?

28.2 Há em cada ministério ou órgão um serviço central para autorização de publicações?

28.3 Existe uma unidade no nivel nacional para supervisionar as publicações? Como opera?

3. Meios de publicação e distribuição

A. Impre'ssão

31.1 Existe uma imprensa central do govêrno? Qual a sua condição oficial? Possui ela monopólio de jure ou de facto?

31.2 Há outras imprensas oficiais? Qual a sua condição?

31.3 Há oficinas de mimeografia, "offset», etc., nos atuais órgãos administrativos?

31.4 Recorrem as autoridades administrativas ao setor privado? Em que condições, e.g., contratos, concorrências?

31.5 Há regulamentos para padronização de tipos, tamanho, marcas de identificação do serviço ou serviços que editam. as publicações?

B. Edição

32.1 Está a edição de publicações oficiais separada de sua impressão?

32.2 Existe' serviço central do govêrno que possua monopólio de edição, quer de jute quer de facto?

32.3 Existe em cada ministério ou órgão um serviço central destinado a coordenar os trabalhos de edição?

( I) diretamente?

(II) através de órgãos correlatos ou repartições públicas: vinculadas?

32.4 Pode-se recorrer a editôres particulares?

Em que condições, e.g. a assinatura de um número determinado de exemplares, subvenção parcial ou total, fornecimento de material editorial em troca de um certo número. de exemplares?

32.5 Quem determina o número de exemplares?

32.6 Aceita-se publicidade paga? É permitido ou proibido angariar assinaturas?

C. Problemas relativos a «Copyright»

33.1 Caem as publicações oficiais no domínio público logo após: serem editadas, ou apenas algumas delas? Como se procede à distinção? Possui o govêrno qualque'r solução para a reprodução errada de textos oficiais? 
33.2 Preserva-se o «copyright» do Estado? Menciona-se o «copyright» nas publicações, consoante 0 disposto na Convenção Internacional de «Copyright» de 1952?

33.3 Permite-se reprodução de matéria publicada?

33.4 Quando de textos firmados pelos autores indica o govêrno, em suas publicações, assumir a responsabilidade dos mesmos?

D. Distribuição nacional

34.1 Vendas

34.11 Ficam as vendas afetas ao serviço encarregado da publicação ou a algum outro órgão?

34.12 Que'm estabelece o preço de cada publicação, ou de assinaturas de jornais, e em que base?

34.13 Há publicações das quais certos órgãos administrativos e comunidades locais são obrigados a tomar assinaturas? Em caso afirmativo, em que condições?

34.14 Está a distribuição a comerciantes de livros de'vidamente organizada? Em que base? Está a dedução que lhes é concedida em conformidade com as práticas dêsse comércio?

34.15 Está organizada a publicidade de vendas? Por quem? Quais os métodos empregados, e.g., anúncios na imprensa, rádio, listas gerais de livrarias, boletins do serviço ou serviços editôres, prospectos, anúncios em outras publicações do govêrno?

\subsection{Intercâmbio}

34.21 Há intercâmbio direto entre os serviços? Em caso afirmativo, em que condições?

34.3 Distribuição de cortesia

34.31 Que tipos de publicação são distribuidos gratuitamente e que principios regem essa distribuição?

34.32 É êsse tipo de distribuição efetuado por um órgão central ou por cada serviço editor?

34.33 Está sujeita a fiscalização? Por cada órgão, individualmente, ou em escala nacional?

34.34 Além de comunicados à imprensa, há outras categorias de documentos que sejam distribuídos à imprensa? Em que condições?

34.4 Originais (duty copies) e acesso público

34.41 Há necessidade de exemplares originais? Em caso afirmativo, quantos? Quem os deposita e onde? Ficam as publicações assim obtidas à inteira disposição do público? Em um ou em vários centros?

34.42 Há depósitos obrigatórios organizados? Na capital do país? Em outros locais? Qual a legislação que os instituiu? Qual o órgão responsável pelos mesmos? 
E. Distribuição Internacional

35.1 Vendas

35.11 Como se procede em relação a vendas para o exterior?

Há agentes de vendas?

35.2 Intercâmbio

35.21 Assinou o govêrno de seu país a Convenção de Bruxelas de 15 de março de 1886 sôbre intercâmbio. internacional de publicações oficiais?

Ratificou êle a Convenção de Paris de 3 de dezembro de 1958 sôbre a mesma questão?

(Os textos dessas convenções foram reproduzidos em documentos da UNESCO e em outros).

35.22 Assinou o govêrno qualquer acôrdo bilateral para o intercâmbio de publicaçõés oficiais? Com que paises e em que datas?

35.23 Existe alguma unidade central encarregada dêsse intercâmbio?

35.24 Há intercâmbios diretos efetuados entre serviços semelhantes em diferentes Estados? Quem os autoriza?

São êles levados ao conhecimento de um órgão central, responsável pela fiscalização da distribuição em geral?

35.3 Distribuição de cortesia

35.31 Mantém cada órgão o contrôle integral da distribuição de suas publicações?

35.32 É o envio gratuito de exemplares levado ao conhecimento de um órgão central, responsável pela fiscalização da distribuição em geral?

F. Relação Nacional de Publicações Oficiais

36.1 Existe algum catálogo geral das publicações do govêrno? Qual o órgão que o elabora e qual sua incidência?

36.2 Há catálogos especiais para determinados órgãos ou para: certos serviços? Qual sua incidência e qual a forma de distribuição?

36.3 Como é feita a publicação dos catálogos e a que'm são enviados?

Tema III - Organização governamental para o desenvolvimento econômico

1. Aspectos gerais

11. Quais os principais objetivos das diretrizes, planos e programas governamentais de desenvolvimento econômico (e.g. produção industrial ou agricola, alto nivel de emprêgo)? 
12. Descreva as técnicas, métodos e processos (e.g. nacionalização, criação de emprêsas públicas, contrôle ou auxílio ao setor privado) que se empregam para atingir o objetivo ou objetivos.

13. Quais as relações e os mecanismos para a coordenação de unidades nacionais e territoriais, com vistas ao desenvolvimento econômico, principalmente em Estados federais ou altamente descentralizados?

14. Qual a base juridica da organização governamental para desenvolvimento econômico (Constituição, lei, estatuto, etc.)?

2. Elaboração de politica

21. Que autoridade' (e.g. Congresso, Chefe de Estado, Ministério) decide sôbre a necessidade de uma politica de desenvolvimento econômico?

22. Quem determina a política de desenvolvimento econômico a ser seguida? O Ministério, uma comissão interministerial, um ministério especial, o Ministério da Fazenda?

23. A quem cabe assessorar sua elaboração? Escritórios especializados, técnicos, représentantes de interêsses econômicos e de trabalhadores?

24. Quem aprova a política? O Congresso, o Chefe do Estado, o Ministério?

25. Ficam outras autoridades do Estado e individuos legalmente vinculados a essa política?

3. Planos ou programas gerais, especiais e pormenorizados

31.1 (a) Quem elabora o plano geral do país, se houver, para execução da politica geral: comissão interministerial, «supraministério», comissário, junta especial de planejamento? (b) Quem elabora os planos especiais para cada uma das regiões (horizontais) ou para cada setor econômico (vertical)?

(c) Quem elabora o plano ou programas pormenorizados ou operacionais (por um ano ou por qualquer outro período)?

31.2 (a) Consultam-se outros órgãos públicos ou privados, nacionais ou regionais, instituições científicas, sindicatos trabalhistas, bem como órgãos encarregados da execução do programa, ou che'ga-se a acôrdos com os mesmos?

(b) Como se procede à coordenação com planos e programas de outras regióes e setores econômicos e, se houver necessidade, com órgãos régionais, e como se evita duplicação de esforços?

(c) A quem cabe dirimir controvérsias?

31.3 (a) Fazem-se contatos com países vizinhos ou outros países distantes, e com organismos especializados do setor econômico? 
(b) Assumem êsse's contatos a forma de planos ou pro gramas?

(c) Qual a organização existente para o emprêgo de recursos externos e internacionais?

31.4 Está o povo informado sôbre os planos e/ ou programas e toma parte nos mesmos? Em caso afirmativo, de que maneira?

32. (a) São os pormenores constitutivos dos programas elaborados por etapas?

(b) Determina-se o periodo de tempo para execução de cada operação?

(c) Até que ponto estão as autoridades que elaboram o programa legalmente sujeitas às decisões tomadas pelas autoridades que as precederam?

(d) Que participação têm no sistema a legislação e as decisões administrativas?

33. (a) A quem cabe aprovar os planos e/ ou programas definitivos? (b) Quais os podêres do Ministério da Fazenda, do Tribunal de Contas, ou de outros órgãos de contrôle financeiro?

34. De onde provêm os recursos para os planos e' programas: verbas orçamentárias, empréstimos, fundos especiais, órgãos externos e internacionais, acôrdos internacionais, firmas comerciais ou outras fontes?

4. Unidades de planejamento ou programação

41. Quantas unidades de planejamento ou programação têm a seu cargo a elaboração dos programas?

(a) Qual a característica da unidade de planejamento: a mesma autoridade responsável pelos planos gerais e/ ou especiais, órgão estatal já existente' (ministério ou outra repartição), unidade ou instituição especializada (inclusive entidades legais formalmente separadas do Estado, mas de fato na dependência dêle), ou instituição independente?

(b) Está a unidade igualmente encarregada de desempenhar tarefas administrativas?

42. (a) Descreva a organização interna e os serviços externos da unidade.

(b) Qual o critério de seleção do pessoal, quais os seus antecedentes educacionais e profissionais e qual a sua situação jurídica?

(c) Possui a unidade' pessoal especializado?

(d) Qual a posição do chefe?

(e) Quais os serviços que competem ao chefe?

(f) Como estão representados os diversos setores interessados?

(g) Podem técnicos estrangeiros e membros de organizações internacionais fazer parte da unidade?

(h) A quem compete custear a elaboração dos programas? 
5. Execução

51. Está a execução das diretrizes, planos e programas a cargo dos órgãos que os elaboraram, de outras unidade's governamentais, de unidades a serem criadas, de sociedades governamentais ou de economia mista mais ou menos ligadas ao Estado, da cooperação pública, de companhias concessionárias, do setor privado (me'diante auxílios e supervisão), ou a cargo de uma combinação de todos? Quais as medidas tomadas para estimular os trabalhadores?

52. Quem controla a concessão de contratos e a distribuição de fundos?

53. Podem os órgãos intermediários autorizar adiantamentos?

54. Qual a fôrça jurídica dos planos e/ ou programas?

55. Quais os recursos disponiveis contra os ajustes descritos?

6. Supervisão

61. Como se processa a supervisão administrativa, financeira, ou de outra natureza, da execução das diretrizes, planos e programas?

A quem cabe essa supervisão?

62. Quais as penalidades impostas em casos de não cumprimento dos planos e programas?

63. A quem cabe dirimir controvérsias?

64. Há contrôlé por parte do Congresso?

7. Revisão

71. Será possivel proceder-se a uma revisão ou integração quando as diretrizes, planos ou programas já tiverem sido aprovados?

72. Quais os órgãos que acompanham sua execução, avaliam seu andamento e podem fazer e aprovar modificações?

73. Prevêem as diretrizes, planos ou programas soluçóes alternativas, ou cada reajustamento exige replanejamento? 